\title{
Investigation of lake drying attributed to climate change
}

\author{
M. Abbaspour • A. H. Javid - S. A. Mirbagheri • \\ F. Ahmadi Givi $\cdot$ P. Moghimi
}

Received: 20 July 2010/Revised: 27 November 2011 / Accepted: 2 January 2012/Published online: 13 March 2012

(C) CEERS, IAU 2012

\begin{abstract}
In recent decades, climate change has been of great concern due to its effect on water level and its impact on aquatic ecosystems. Urmia Lake, the largest inland wetland in Iran, has been shrinking. There is a great concern whether it will dry up like the Aral Sea. Therefore, a hydrodynamic model has been developed to simulate the condition of Urmia Lake. The model has been validated using the known annual data on precipitation, evaporation, run off, river discharges and water level which are available for the last 35 years. Different hydrological conditions regarding lake input and output data were tested and water depth was calculated using bathymetry to predict waterlevel fluctuations in the future. The results predict that the water level will decrease continuously. The lake will be dried up in about 10 years if very dry conditions continue in the region. The drought speed cannot be reduced and there is no potential to develop a water-usage program. Besides, the lake water depth decrease is more slightly, applying alternate wet and dry-period conditions. In some hydrological conditions there is a good potential to consider water development projects. The sensitivity analysis of different parameters indicates that the lake is highly sensitive to river discharges, which implies that the water development project plans will disturb the lake ecosystem if implemented up to 2021 and integrated watershed
\end{abstract}

M. Abbaspour · A. H. Javid · P. Moghimi ( $\square)$

Department of Environmental Engineering, Science and

Research Branch, Islamic Azad University, Tehran, Iran e-mail: moghimi.parisa@gmail.com

S. A. Mirbagheri

Department of Civil Engineering, KNT University, Tehran, Iran

F. Ahmadi Givi

Institute of Geophysics, University of Tehran, Tehran, Iran management plan for the lake can change the condition by regulating the dam output.

Keywords Climate change - Ecosystem . Level fluctuation · Modeling $\cdot$ Water level

\section{Introduction}

Urmia Lake, located in the Province of Azerbaijan at the north-west of Iran (Fig. 1a), is one of the largest permanent hyper-saline lakes in the world and it is an important natural asset with considerable cultural, economic, aesthetic, recreational, scientific, conservation and ecological value (Karbassi et al. 2010, Kelts and Shahrabi 1986, Eimanfar and Mohebbi 2007). It is a closed-basin wetland for which the only outlet is evaporation and the inlet is precipitation, rivers, runoff flow and negligible groundwater inflow.

Due to 15 years of progressive dry climate (relatively lower precipitation and higher temperature in Fig. 2a, b) and more water usage, the lake water level has been decreased about 6 m (West Azerbaijan Water Authority Report 2010) and also there is a great concern about its impending drought in the future similar to the Aral Sea. Alesheikh et al. (2005) mapped the coastline changes for Urmia Lake in 1989, 1998 and 2001 concluding that the lake's great decrease in water depth from 1998 to 2001 ( $3 \mathrm{~m})$ is related to the lake's hydrologic budgets. The hydrological studies on its watershed (WRI 2005; WWA 2005) indicate that in the recent years the water balance has been negative. The lake level has dropped lower than its ecological level of $1,274.1 \mathrm{~m}$ (Nazaridoust 2006) with concomitant deterioration of the environmental balance in the region (the lake is supposed to be the most convenient place for many rare aquatic species and is the main habitat for the endemic Iranian brine shrimp, 


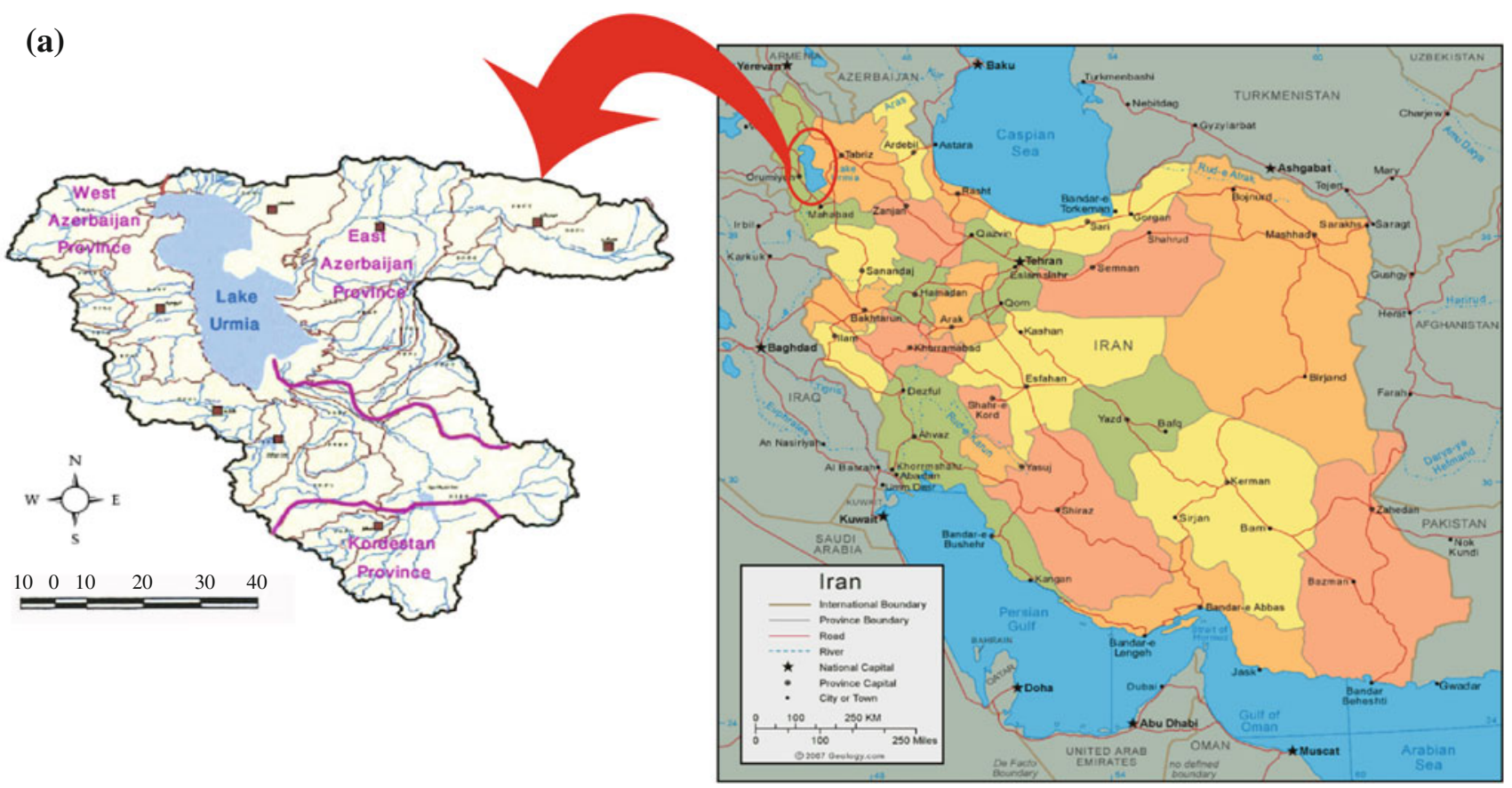

(b)

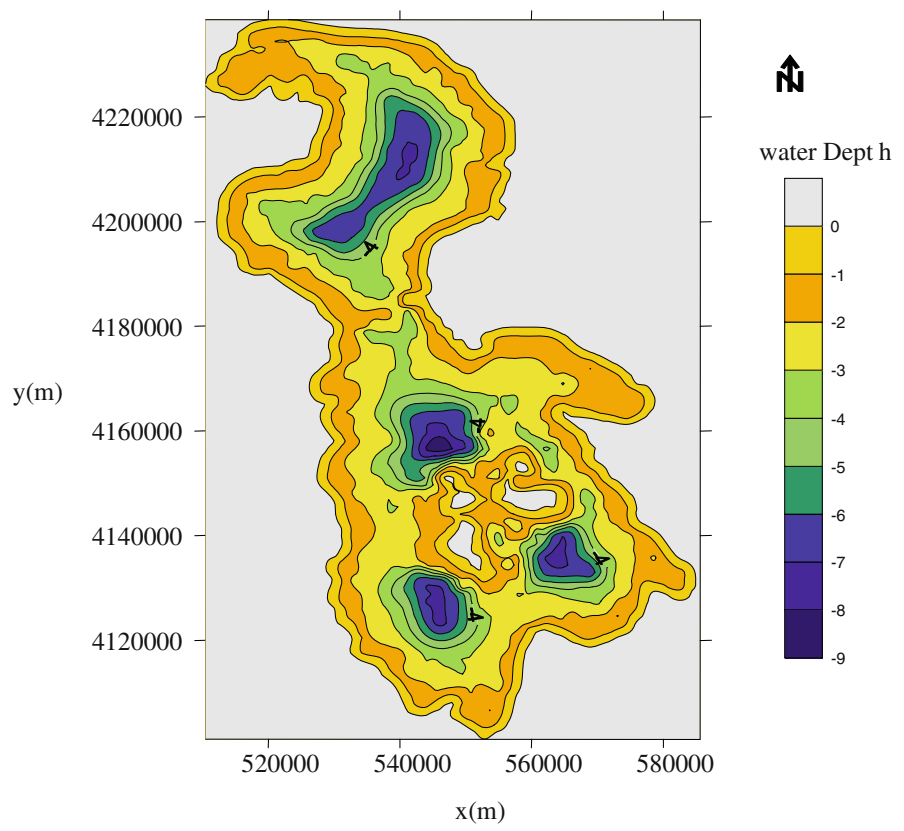

Fig. 1 a Urmia Lake Basin on Iran map, input rivers. b Bathymetry of Urmia Lake (UTM coordinates)

Artemia urmiana and is a protected aquatic environment (Ahmadzadeh Kokya et al. 2011, Karbassi et al. 2010).

Its drought will likely result in Artemia perishing, wildlife menace, salt storms, ambient temperature increase, reduction in tourism and economic and social loss. Therefore, it is important to predict the future water level of the lake to sustain its environmental condition and to consider water resources management strategies in the region (study on the integrated watershed management plan for the lake and its regulation started in 2010).
In addition, it is important for the water authorities and the beneficiaries of the lake to be aware of potential draughts and how much influence the drought may have on water level to prevent economic loss in the basin. Fuzzy approach (Altunkaynak and Şen 2007), artificial neural network (Vaziri 1997) and probable water level curves (Woodbury and Padmanabhan 1989) are some methods used to predict the water level variations. Delavar 2005 used an artificial neural network method to predict Urmia Lake's water level during 2006-2099 due to climate 
Fig. 2 a Mean yearly temperature (Urmia station) and water level variations (1967-2005) in Urmia Lake. b Mean yearly precipitation and water level (1967-2005)

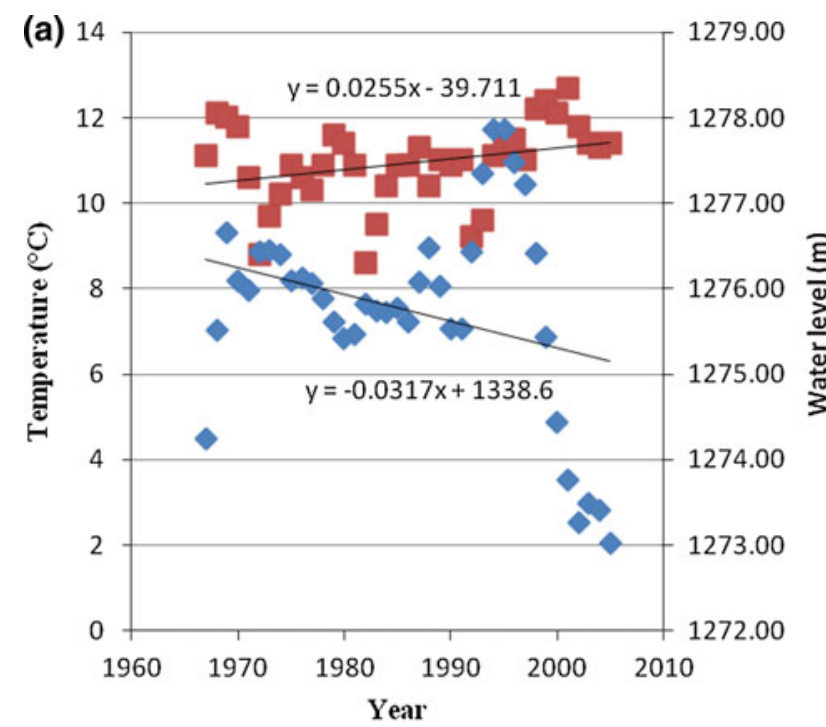

Temperature of urmia station

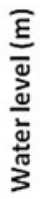

- observed water leve

- Linear (Temperature of urmia station)

Linear (observed water level)

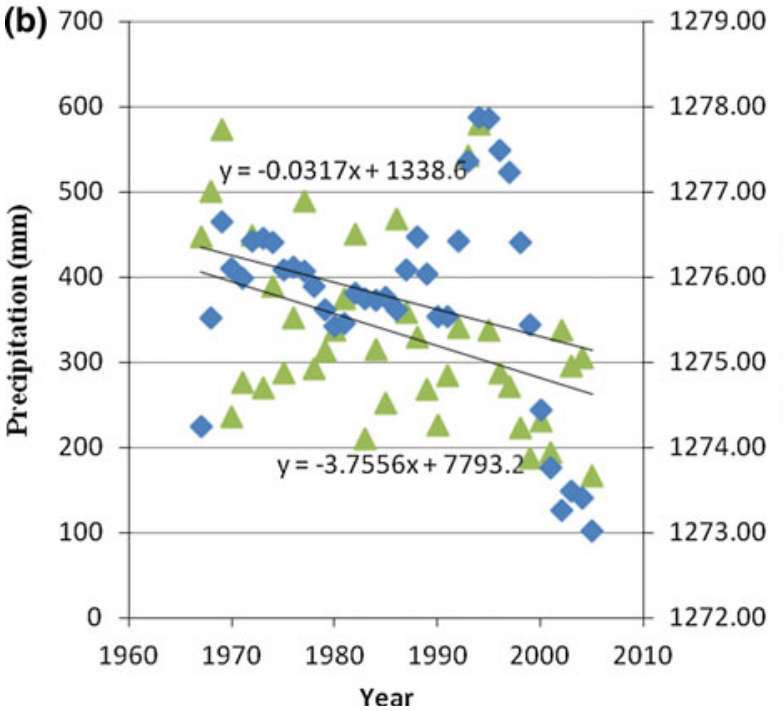

A Precipitation of urmia station

- observed water level

- Linear (Precipitation of urmia station) - Linear (observed water level) change. Since an approximate water level/volume formula was applied and the severe drought data were not used, it is necessary to simulate the future lake water level by applying a more flexible method using real conditions and taking into account its bathymetry. To apply bathymetry and the drought conditions, hydrodynamic models (2D or 3D) can be used. 3D models can present more reliable and rational hydrodynamic simulations (Zeinoddini et al. 2009). Here, a 3D model (FVCOM) capable of accurately solving the scalar conservation equations along with topological flexibility provided by unstructured meshes was used (Chen et al. 2003). Previously, such models were normally used for a specific condition (extreme condition: tsunami simulation or calibration cases: tidal waves (Zhaoqing and Tarang 2008) and limited duration (for several hours or days), but not for water level predictions over a period of several years.
In this study (carried out within 2010-2011), a scientific model of natural and engineered environments has been applied, which is a relatively new approach that combines a hydrodynamic model with different hydrological periods to predict the coming year's water level fluctuations in the Urmia Lake; to find its environmental condition and probability of its drought in near future; and in selection of the scenarios to take the most fitted one to evaluate the future changes in the environment.

\section{Materials and methods}

Model description

An unstructured grid finite-volume three-dimensional (3D) primitive equation ocean model (FVCOM) has been used 
for studying the water-level variations in Urmia Lake. The irregular bottom slope is represented using a $\sigma$-coordinate transformation and the horizontal grids comprised unstructured triangular cells (Chen et al. 2003). The equations of conservation of mass, momentum and turbulent closure in $\sigma$ coordinate system are used in the hydrodynamic model based on sigma transformation to describe the flow and water-level variations (according to Blumberg and Mellor 1978, 1987). FVCOM is solved numerically by a second-order accurate discrete flux calculation in the integral form of the governing equations over an unstructured triangular grid. This approach combines the best features of finite-element methods (grid flexibility) and finite-difference methods (numerical efficiency and code simplicity). A second-order accurate four-stage RungeKutta time-stepping scheme is used for external mode time integration while the first-order Euler forward scheme is used for internal mode time integration. A second-order accurate upwind scheme, which is based on piecewise linear reconstruction of dynamic variables is used for flux calculation of momentum and tracer quantities (Kobayashi et al. 1999; Hubbard 1999).

Comparisons (Chen et al. 2007; Huang et al. 2008) between FVCOM, POM and ECOM-si solutions for a variety of test cases for lake (wind induced long-surface gravity waves in an idealized circular lake and for freshwater discharge experiments on idealized shelves in a circular lake) demonstrate that the finite-volume method used in FVCOM provides a more accurate simulation than the two finite difference models in cases with complex coastal geometry and steep bottom slopes. In particular, the finite volume methods ensure volume, mass and tracer conservation in the individual control volumes and the unstructured triangular grid can be closely fit to an irregular coastline and model domains, resulting in highly accurate numerical solutions in even quite complex model geometries. With second-order accuracy, FVCOM combines the advantage of a finite element method for geometric flexibility and a finite difference method for simple discrete computation. Grummp open source code software has been utilized in grid generation which uses Delauny method, and was developed by British Columbia University.

\section{Model inputs}

Urmia Lake is a closed-basin lake (Fig. 1a) with a flow regime highly dependent on annual climate conditions. Hence, the applied model inputs are annual meteorological and hydrological data including precipitation, evaporation, river and runoff discharge to the lake. The stations, used in this study, are Urmia Lake Basin weather and hydrometric stations with more than 30 years of daily recording. It should be noted that all of these parameters are retrieved from the approved report by West Azerbaijan (WRI 2005) for water balance studies in the water basin of the lake (during 1967-2001). The hydrological studies on its watershed (WRI 2005; WWA 2005) and investigation, comparison and conclusion on data reliability of these studies were already reported by Hashemi (2008) which was prepared for conservation of wetlands UNDP/GEF program in Iran. This report clarifies that the WRI calculations and WWA (2005) studies show differences in evaluating the water input to the lake. Lake bathymetry (ABNIROO 1994) prepared by some navigations on the lake using eco-sounder is applied in the model for 1967 for its related water level 1,274.25 m (Fig. 1b).

\section{Calibration and validation}

The model predictions are calibrated by comparing the output data with empirical data. If only one data set is available (as in this study) a split data set is recommended (e.g., random selection of a calibration dataset and a validation dataset from the data available) (Bates et al. 2006). Here, the yearly water-level fluctuations from 1967 to 1986 (observational data for 20 years) have been used to calibrate the model and the data during 1987-2001 (15 years) have been used to validate the model results. Predicted and observed data comparisons in this text were made based on both RMS and RMS (\%) errors defined as:

$$
\begin{aligned}
& \operatorname{RMS}=\sqrt{\frac{1}{N-1} \sum_{i=1}^{N}\left[W_{m}(i)-W_{0(i)}\right]^{2}} \\
& \operatorname{RMS}(\%)=\sqrt{\frac{1}{N-1} \sum_{i=1}^{N}} \\
& \quad\left[\frac{W_{m}(i)-W_{m, \min }(i)}{W_{m, \max }(i)-W_{m, \min }(i)}-\frac{W_{0}(i)-W_{0, \min }(i)}{W_{0, \max }(i)-W_{0, \min }(i)}\right]^{2}
\end{aligned}
$$

In the model data comparison case, $W_{\mathrm{m}}$ and $W_{\mathrm{o}}$ are the model predicted and observed mean water elevation, respectively. Here, $N$ is the sample number and the subscripts "max" and "min" indicate maximum and minimum of the water elevation.

In this study, the lake model grid resolution (unstructured triangular mesh) varies from 0.5 to $1.5 \mathrm{~km}$ from the boundary limit to the internal part of the lake as time resolution is 1 year. The number of grids is 3,228 and the number of elements is 5,673. Model has been set up to run annually for a total 35 year data.

\section{Scenarios}

Widespread and severe drought conditions in Asia, Latin America and the Caribbean in 2000 raised serious concerns 
Table 1 Scenarios for different hydrological period simulation continued in near future (for 33 years)

\begin{tabular}{|c|c|c|c|c|c|c|}
\hline \multirow[t]{3}{*}{ Scenarios } & \multicolumn{6}{|c|}{ Data taken from real condition in years } \\
\hline & Very wet & Wet & Dry & Mean & Very dry & Dry \\
\hline & 1993 & 1994 & 1995 & 1996 and 1997 & $1998-2000$ & 2001 \\
\hline 1 & & $\checkmark$ & & & & \\
\hline 2 & & & & $\checkmark$ & & \\
\hline 3 & & & & & & $\checkmark$ \\
\hline 4 & & & & & $\checkmark$ & \\
\hline 5 & & & & & $\boldsymbol{V}$ & $\checkmark$ \\
\hline 6 & & & & $\checkmark$ & $\checkmark$ & $\checkmark$ \\
\hline 7 & $\boldsymbol{v}$ & $\boldsymbol{\nu}$ & $\boldsymbol{v}$ & $\checkmark$ & $\checkmark$ & $\checkmark$ \\
\hline
\end{tabular}

about the continuing vulnerability of the world community to extended periods of droughts and water shortages. Especially hard hits were Afghanistan, Bulgaria, Iraq, Islamic Republic of Iran and parts of China (Sivakumar and Wilhite 2002).

The studies (WRI 2005) on discharge of six selected rivers flowing to the lake show the different hydrological conditions in different years using 3-5- and 7-year moving average curves. As seen in Table 1, the lake has encountered alternately very wet, wet, average, dry and very dry periods. After the wet period of 1994 and by the beginning of dry period, the river input and the lake water level have decreased continuously. The reduction in water level due to climate change is $70 \%$ relative to water usage (reported by the Iranian Power Ministry, head of water planning office) (Daemi 2009). Since it is not clear how much the drought can affect the lake level in near future, the present condition has been used to set up a model for different scenarios as illustrated in Table 1. The scenarios can be applied for 33 years (2002-2035) and predict conditions beyond the empirical hydrological data from 1993 to 2001.

The following scenarios (Table 1) are used to find water level fluctuations (during 2002-2035) due to climate change trend, then the scenario which best fit the lake fluctuation during (2002-2010) is selected to set up the model for other conditions:

1. Model run for continuous wet period.

2. Model run for continuous mean-period.
3. Model run for continuous dry period.

4. Model run for continuous very dry period.

5. Model run for alternate very dry/dry period.

6. Model run for alternate mean/very dry/dry period.

7. Model run for alternate very wet/wet/dry/mean/very dry/dry period.

The following scenarios are used to analyze the waterlevel sensitivity for both different hydrometric and climatic parameters (during 1967-2001) to recognize the influence of precipitation on the lake compared with river discharge by imposing the climate change trends:

(A) Model run; including evaporation, precipitation, river and runoff.

(B) Model run; including evaporation and river.

(C) Model run; including evaporation, precipitation and runoff.

\section{Results and discussion}

Model validation

The simulation performed reasonably in capturing water level variability in the lake. Comparison between observed and calculated water level (Table 2; Fig. 3a, b) shows eight and ten percent RMS errors, respectively.
Table 2 Comparison between observed and calculated water levels

\begin{tabular}{|c|c|c|c|c|}
\hline & \multicolumn{2}{|c|}{ Model calibration (1967-1986) } & \multicolumn{2}{|c|}{ Model verification (1987-2001) } \\
\hline & $\begin{array}{l}\text { Calculated } \\
\text { water level }\end{array}$ & $\begin{array}{l}\text { Observed } \\
\text { water level }\end{array}$ & $\begin{array}{l}\text { Calculated } \\
\text { water level }\end{array}$ & $\begin{array}{l}\text { Observed } \\
\text { water level }\end{array}$ \\
\hline Average (m) & $1,275.44$ & $1,275.86$ & $1,276.92$ & $1,276.26$ \\
\hline $\operatorname{Max}(\mathrm{m})$ & $1,276.18$ & $1,276.66$ & $1,278.73$ & $1,277.87$ \\
\hline $\operatorname{Min}(m)$ & $1,274.25$ & $1,274.25$ & $1,273.99$ & $1,273.76$ \\
\hline Std & 0.45 & 0.52 & 1.39 & 1.20 \\
\hline RMS & 0.47 & & 0.79 & \\
\hline RMS error $(\%)$ & 10 & & 8 & \\
\hline
\end{tabular}


Fig. 3 a Comparison between observed and calculated water and $\mathbf{b}$ during 1987-2001 levels (m) (during 1967-1986)
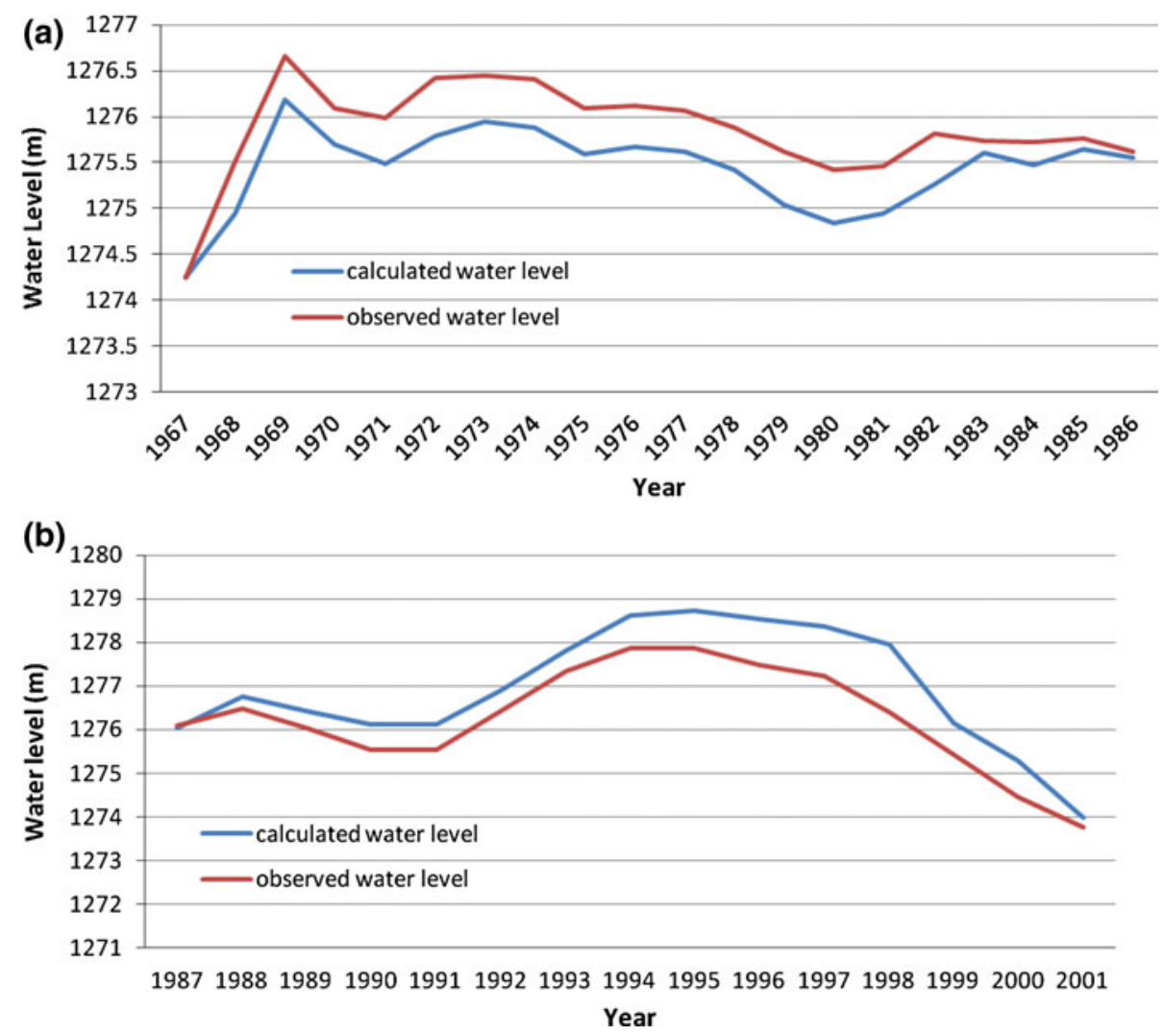

The difference between observed and calculated waterlevel data is explained as being a result of errors in the bathymetry (which are the available data, obtained by some navigations on the lake using eco-sounder) applied to run the model and the difference between the evaporation from a pan for fresh water and Urmia Lake's salty water in different levels (despite some corrections made by WRI 2005), which would be expected to affect the water level more than other components.

The water with high salinity and low salinity has different evaporation rates (according to Mohammadi 2004, who investigated Urmia Lake's evaporation at one station during 1989-2001). In WRI investigations, a constant coefficient has been applied to the evaporation from the pan fresh water to obtain the evaporation amount of saline water (here used as input for the model). This constant coefficient is almost equal to the slope of regression line obtained by Mohammadi. According to Mohammadi, there is a nonlinear relation between evaporation from the lake and from the pan; the more salinity in the lake water, the lower evaporation of the lake as opposed to fresh water in the pan. This may cause a deviation from the observed water level to the predicted one.

To reduce errors, accurate evaporation rates must be measured using trials of differing conditions (various salinity concentrations, humidity, atmospheric pressure, solar radiation, etc.) and subsequently using them as a time series for model input. In addition, determining an accurate hydrometric navigation may reduce the mentioned errors in the lake bathymetry.

Urmia Lake's fate due to climate change

Although some water development projects were implemented in the past (in 1971 commissioning of two dam with 1 billion $\mathrm{m}^{3}$ capacity was started), the lake water level had been increasing continuously due to good precipitation (the highest water level in the lake occurred in 1996) and new water development projects were ratified to be implemented up to 2021 (Daemi 2009). By outbreak of dry period in recent years along with increased water usage due to drought and new projects in the region, a severe drop occurred in water level so that the river inflow became negligible. In this research, simply the impact of different hydrological conditions (dry or wet periods), but not the water development projects, have been considered (planned up to 2021). The applied data in the model belong to the period that the climate change portion in lake drought is about 70\% compared with the projects (Daemi 2009) (as described in "Scenarios"). The results (Table 3; Fig. 4) reveal that only in scenarios 1,2 and 7, the lake condition is environmentally desirable and the water level increases to more than the ecological water level $1,274.1 \mathrm{~m}$ (Nazaridoust 2006). In other scenarios, there is a continuous 
Table 3 Model run results for different scenarios

\begin{tabular}{|c|c|c|c|c|c|c|c|c|c|c|}
\hline \multirow[t]{2}{*}{ Scenarios } & \multicolumn{5}{|c|}{ Hydrological condition } & \multicolumn{4}{|l|}{ Statistics } & \multirow[t]{2}{*}{ Drought condition } \\
\hline & Very wet & Wet & Mean & Dry & Very dry & Average (m) & $\operatorname{Max}(\mathrm{m})$ & $\operatorname{Min}(\mathrm{m})$ & Std & \\
\hline 1 & & $\times$ & & & & $1,284.98$ & $1,296.55$ & $1,273.27$ & 7.01 & \\
\hline 2 & & & $\times$ & & & $1,273.30$ & $1,273.34$ & $1,273.11$ & 0.06 & \\
\hline 3 & & & & $x$ & & $1,271.99$ & $1,273.27$ & $1,271.65$ & 0.43 & \\
\hline 4 & & & & & $x$ & $1,266.36$ & $1,273.27$ & $1,264.97$ & 2.54 & Will be dried \\
\hline 5 & & & & $\times$ & $\times$ & $1,266.62$ & $1,273.27$ & $1,264.97$ & 2.64 & Will be dried \\
\hline 6 & & & $\times$ & $\times$ & $\times$ & $1,269.79$ & $1,273.27$ & $1,267.74$ & 1.52 & \\
\hline 7 & $\times$ & $\times$ & $x$ & $x$ & $x$ & $1,274.66$ & $1,276.02$ & $1,272.88$ & 1.09 & \\
\hline
\end{tabular}

Fig. 4 Comparison of calculated water level $(\mathrm{m})$ in different hydrological period condition
Fig. 5 Comparison between observed and calculated water levels (m) in dry, very dry, alternate very dry/dry and alternate mean/very dry/dry period condition (2002-2010)

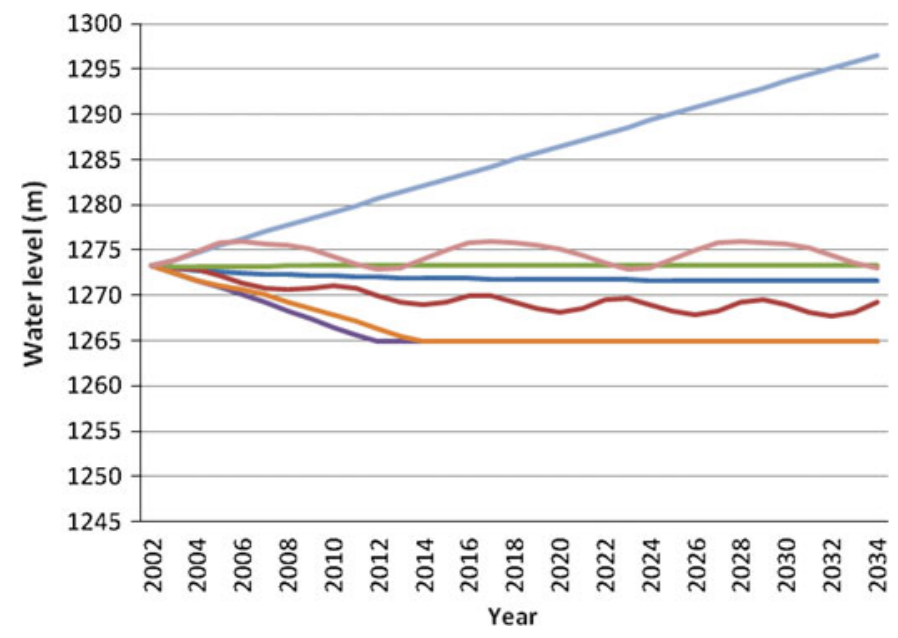

$\longrightarrow$ dry

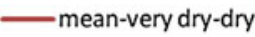

mean

- very dry

- very dry-dry

wet

wet-very wet-meanvery dry-dry

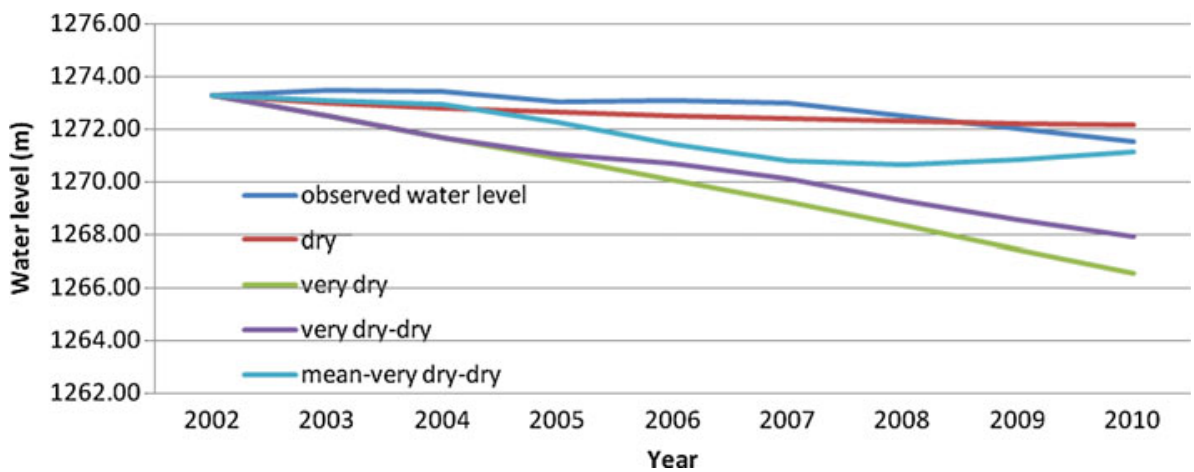

decline in water level with undesirable environmental conditions. The conditions become progressively worse in scenarios 3, 6, 5, and 4 .

The lake will be dried only in continuous very dry or alternate very dry/dry conditions (scenarios 4 and 5). It will never be dried completely in other conditions, but will fall below ecological level in some cases. In all cases, except wet period (scenario 1), there is no potential for new water use or water development project plans.

After these simulations, the recorded data were compared (Fig. 5) with the output from different scenarios (2002-2010) to select the scenarios that best fit the current condition. These scenarios are used to predict the future of 
the lake due to drought in this section and water usage in the next section (nearly no river discharge, as happened in summer 2010).

As it can be seen, the current trend of water level decrease is to some extent similar to the continuation of dry period or continuation of alternate mean/very dry/dry period in future (scenarios 3 and 6). In 2035, the water level will reach to $1,271.62 \mathrm{~m}$ with the depth of $6.67 \mathrm{~m}$ (Fig. 4) if the former condition surrounds the region, and it will experience sinusoidal variations of which the lowest depth is $2.77 \mathrm{~m}$ and water level is $1,267.72 \mathrm{~m}$, if the latter condition surrounds the region. The water level decrease due to the climate change in both scenarios is dramatic and a profound adverse impact on the environmental balance is predicted in the region.

In this research, the mean annual water level has been simulated as $1,271.99 \mathrm{~m}$ in dry period, and $1,269.79 \mathrm{~m}$ in mean/very dry/dry period which shows a better agreement with the actual condition than the previous study (Delavar 2005). The research by Delaver shows that using the climate change software (GCM) output for scenarios A2 and B2, the water level in June 2010 will be finally decreased to $1,274.6 \mathrm{~m}$ in scenario B2 and also to $1,275.08 \mathrm{~m}$ in scenario A2; the mean annually water level is $1,274.67 \mathrm{~m}$ with deviation of $0.83 \mathrm{~m}$ and $1,274.9 \mathrm{~m}$ with deviation of $0.5 \mathrm{~m}$, for scenario B 2 and A2, respectively. Water authorities reported the water level to be $1,271.5 \mathrm{~m}$ at the end of summer 2010.
Lake sensitivity to input parameters

Considering the precipitation as the only lake input (scenario $C$ : no river input), the lake water level will decrease (Table 4; Fig. 6) and dry in 10 years. This means that precipitation on the lake and related run off are very less than evaporation, so that the lake will be dried soon. Considering the river discharge as the only lake input (scenario B: no precipitation on the lake), the lake water-level trends will be to some extent similar to the actual condition (scenario A), though its level will decrease about $4 \mathrm{~m}$.

The results show that the lake is more sensitive to river discharge than precipitation on the lake and its related run off. This means that the lower precipitation on the watershed will result in a lower river and precipitation input to the lake, thereby a larger decrease in water level. Since there is no other modeling prediction on the annual lake water level in the future, only neural network research results have been used for comparison. The results of Delavar (2005) show that the lake is more sensitive to precipitation than river discharge variations.

It can be inferred from Fig. 6 that the lake water level correlates to river input and if drought and irregular water usage reduce the river discharge to the lake, the given balance will be endangered as there is no other water source to amend the level. In addition, the results of different scenarios show that slight precipitation and river discharge in dry and very dry periods, accompanied by

Table 4 Model run for sensitivity analysis of climatic and hydrologic condition

\begin{tabular}{|c|c|c|c|c|c|c|c|c|}
\hline \multirow[t]{2}{*}{ Scenarios } & \multicolumn{4}{|c|}{ Input of the model } & \multicolumn{4}{|c|}{ Statistical calculation } \\
\hline & Evaporation & Precipitation & River & Run off & Average & Max & Min & Std \\
\hline A & $x$ & $\times$ & $x$ & $x$ & $1,276.16$ & $1,278.73$ & $1,274.25$ & 1.17 \\
\hline B & $\times$ & & $x$ & & $1,273.15$ & $1,274.77$ & $1,271.39$ & 0.84 \\
\hline $\mathrm{C}$ & $x$ & $x$ & & $x$ & $1,267.66$ & $1,274.25$ & $1,265.95$ & 2.71 \\
\hline
\end{tabular}

Fig. 6 Calculated water level (m) with different model input (during 1967-2001) for sensitivity analysis

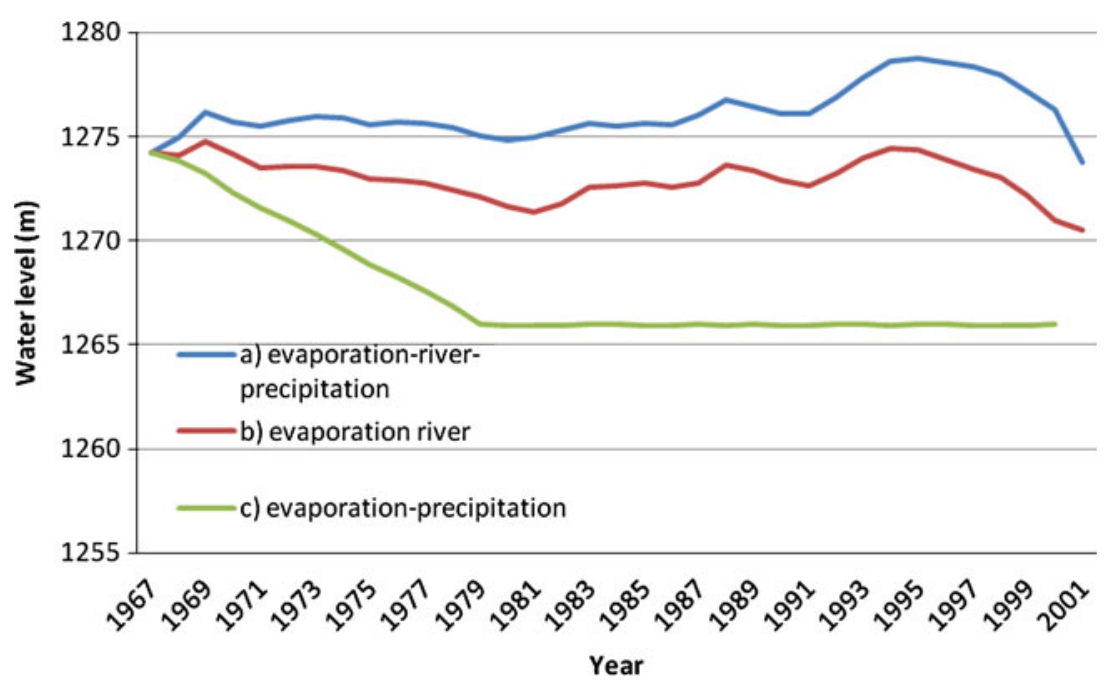


Fig. 7 Calculated water level (m) (2002-2035) without river input after 2010

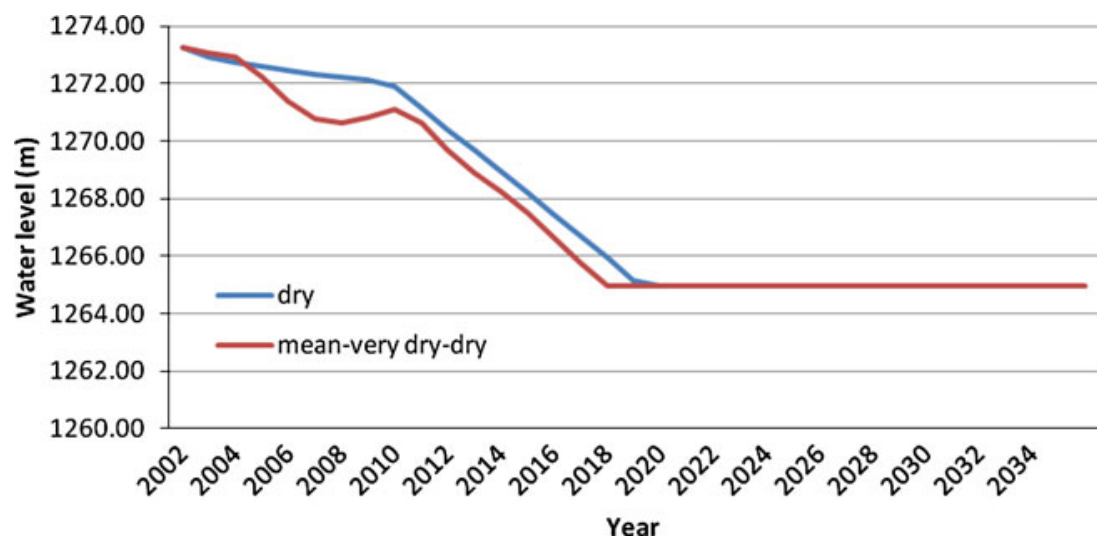

higher evaporation in the basin, cause a large decrease in the lake water level.

There is a great concern regarding the future of the lake's existence in the region due to water usage in addition to climate change trends. In summer 2010, Azerbaijan Regional reported that due to drought in the region as well as extensive water usage, the river discharge input approached zero. This study simulated the condition of dry period and mean/very dry/dry period (selected scenarios: 3 and 6) after 2002, so that the river input is zero after 2010 (Fig. 7). In this figure, it is obvious that the lake will be completely dried after 9 years in the former scenario and after 6 years in the latter. The lake drought is an absolute tragedy for its watershed and also for the country, even if the possible control for the whole environmental condition of the watershed is considered.

\section{Conclusion}

The climate change has been a major concern for decision makers in recent years. The lake's saline water levels which decrease below ecological level are a hazard for the watershed environment. The water level decrease can cause the water salinity to be accumulated and prevent Artemia cysts to be hatched; continuation of this trend in near future will result in Artemia extinction. Therefore, due to demolition of main food resources of birds, especially flamingo, which spawn in the basin, a severe decrease in number of the birds and decreased reproduction will occur. Furthermore, drought causes the major part of the lake to be dried and converted to salt desert. This change can lead to numerous problems in the ecosystem and the climate of the area. The possible outcome should be anticipated by experts in different fields and the predicted losses should be calculated to clarify the impact of its destruction.

The results from comparison of observed data and Delavar predictions show that mentioned method can efficiently identify the variations, since both the bathymetry and the recent hydrological conditions are included to predict the water level. The advantage of present study is its functionality in changing the input parameters on the basis of actual conditions and selecting them in an intellectual manner not on the basis of only repeating the previous data processing without the capability of intervening in the processing procedure. In addition, it is an advantage for decision makers to change the input parameters to decide how to regulate the lake in connection with the climate change (dry or wet period) and reduce the adverse impacts of climate change and drought to select the best water development projects to be implemented up to 2021 . Moreover, this method is not a time-consuming approach and can be used to show the impact of both dam construction and water usage plans more reliably and faster than other methods such as neural network in the future. The uncertainty in bathymetry and the evaporation aroused acceptable errors during model validation. This can be reduced by some studies to obtain the proper evaporation rate in various salinity concentrations, humidity, atmospheric pressure, solar radiation, as well as precise hydrometric navigation.

The major findings in this paper indicate that the predicted water level decrease due to different hydrological periods in selected scenarios is profound and can make a pronounced adverse impact on the environmental balance in the region. The predictions for two selected scenarios show that in 2035 , the water level will fall below the ecological level, which will disturb the lake ecosystem and will preclude more water development projects. The lake is highly dependent on river inflow and is more sensitive to river input than direct precipitation on it. In other words, little precipitation, more evaporation (climate change direct impact) and more water usage (climate change indirect impact) or water development projects implementation in the watershed can reduce the overall river discharge to the lake and accordingly the lake water level. These components should be considered all together to sustain the lake's environmental balance. In the selected scenarios, if 
discharge of all rivers to the lake equals to zero (as happened in summer 2010), the precipitation on the lake will not be enough and the lake will be dried thoroughly in 6-9 years. It means, the climate change has reduced the water input to the lake in a way that the water development projects which were planned to be implemented up to 2021 has been failed.

Integrated watershed management plan for the lake was ratified on April 2010 and it determined that the input to the lake should be regulated to be equal to 3.1 billion $\mathrm{m}^{3}$, according to the head of Iran Environment Department, to reach to the ecological water level. To decrease water projects' impact (planned for 2021) and make decision toward water resources management, it is necessary to do further study to re-plan the water usage (considering the climate change) and make it unharmful to the lake environment. In spite of the Lake regulation program, climate change has had a great influence on input water to the lake, necessitating serious efforts to allocate new water resources (from other watersheds) or new approaches for water usage (higher efficiency irrigation systems) or new methods (clouds enrichment) to save the lake from desertification.

\section{References}

ABNIROO (1994) Consulting engineers. Second phase preliminary studies of Shahid Kalantary Highway cross over Lake Uromiyeh. Report of Ministry of Energy. Tehran, Iran

Ahmadzadeh Kokya A, Pejman AH, Mahin Abdollahzadeh E, Ahmadzadeh Kokya B, Nazariha M (2011) Evaluation of salt effects on some thermodynamic properties of Urmia Lake Water. Int J Environ Res 5(2):343-348

Alesheikh AA, Ghorbani A, Talebzadeh A (2005) Generation the coastline map for Urmia Lake by TM and ETM + imagery. http://www.gisdevelopment.net

Altunkaynak A, Şen Z (2007) Fuzzy logic model of lake water level fluctuations in Lake Van, Turkey. Theor Appl Climat 90:227-233

Azerbaijan Regional Water Authority website (2010). http://www.agrw.ir/

Bates PD, Lane SN, Fergusen RL (2006) Computational fluid dynamics-application in environmental hydraulics. John Wiley \& Sons, Ltd. USA

Blumberg AF, Mellor GL (1978) A coastal ocean numerical model, mathematical modeling of estuarine physics. In: Sundermann J, Holz KP (eds) Proceedings of an International Symposium, Hamburg, August 24-26. Springer-Verlag, Berlin, pp 203-219

Blumberg AF, Mellor GL (1987) A description of a three-dimensional coastal ocean circulation model, In: Heaps N (Ed) Threedimensional coastal ocean models. American Geophysics.

Chen C, Liu H, Beardsley RC (2003) an unstructured grid, finitevolume, three-dimensional, primitive equations ocean model: application to coastal ocean and estuaries. J Atmospher Ocean Tech 20:159-186
Chen C, Huang H, Beardsly RC, Liu H, Xu Q, Cowles G (2007) A finite volume numerical approach for coastal ocean circulation studies: comparisons with finite difference models. J Geophys Res 112:C03018

Daemi AR (2009) The impacts of climate change on Urumie Lake: quarterly periodical. J Inst Iran Cultur Appl Res Rural Heritage Mus Guilan 8:17-22

Delavar M (2005) Analysis and proposing a model for Urmia Lake water level variations and risk analysis of the coastal region. M.Sc thesis. Tarbiat Modarres University, Tehran

Eimanfar A, Mohebbi F (2007) Urmia Lake (Northwest of Iran): a brief review, saline systems. http://www.artemiarc.ir/en/index. php?option=com_content\&task=view\&id=14\&Itemid=1

Hashemi M (2008) Synthesis report: an independent review: the status of water resources in the Lake Uromiyeh Basin. School of Civil Engineering and Geosciences, Newcastle University, UK

Huang $\mathrm{H}$, Chen C, Cowels GW, Winnant CD, Beardsley RC, Hedstorm K, Haidvogel DB (2008) FVCOM validation experiments: comparison with ROMS for three idealized barotropic test problems. J Geophys Res 113:1-14

Hubbard ME (1999) Multidimensional slope limiters for MUSCLtype finite volume schemes on unstructured grids. J Computat Phys 155:54-74

Karbassi A, Nabi Bidhendi G, Pejman AH, Bidhendi ME (2010) Environmental impacts of desalination on the ecology of Urmia Lake. J Great Lakes Res 36(3):419-424

Kelts K, Shahrabi M (1986) Holocene sedimentlogy of hypersaline Urmia Lake, northwestern Iran. Paleogeol Paleoclimatol Paleoecol 54:105-130

Kobayashi MH, Pereira JMC, Pereira JCF (1999) A conservative finite-volume second order accurate projection method on hybrid unstructured grids. J Computat Phys 150:40-75

Mohammadi MA (2004) Relation between fresh and salty water and its impact on Urmia Lake evaporation. West Azerbaijan Water Authority, Ministry of Energy, Iran

Nazaridoust AA (2006) Methodological framework, guidelines and DSS model to calculate the minimal ecosystem water requirements for wetlands: a case study of the International Wetlands in the Lake Uromiyeh Basin. Science and Research Branch, Azad Islamic University, Teharn 2006

Sivakumar MVK, Wilhite DA (2002) Drought preparedness and drought management, ICID, ERWG Conference on "Drought Mitigation and Prevention of band desertification". Bled, Slovenia

Vaziri M (1997) Predicting Caspian Sea surface water level by ANN and ARIMA models. J Waterway Port Coas Ocean Eng 123(4):158-162

Woodbury LH, Padmanabhan G (1989) Estimating terminal lake level frequencies, ASCE. J Water Resour Plan Manag 115(3):321-337

WRI (2005) Integrated water resources management (IWRM) for Lake Uromyeh Basin. Module 1: Data Reports, Iran (PvW-02.048). West Azerbaijan Water Authority, Ministry of Energy, Iran

WWA (2005) The environmental impact assessment and study (quality and quantity) of the Development Projects in the Lake Uromiyeh Basin. The West Azerbaijan Water Authority (WWA), Ministry of Energy, Iran

Zeinoddini M, Tofighi MA, Vafaee F (2009) Evaluation of dike-type causeway impacts on the flow and salinity regimes in Urmia Lake. Iran J Great Lake Res 35:13-22

Zhaoqing Y, Tarang Kh (2008) Modeling of salt intrusion, intertidal mixing, and circulation in a Braided Estuary. J Coas Res 52(Special Issue):171-180 